International Journal of Electrical Engineering and Technology (IJEET)

Volume 11, Issue 4, June 2020, pp. 57-65, Article ID: IJEET_11_04_006

Available online at https://iaeme.com/Home/issue/IJEET?Volume $=11 \&$ Issue $=4$

ISSN Print: 0976-6545 and ISSN Online: 0976-6553

DOI: https://doi.org/10.34218/IJEET.11.4.2020.006

(C) IAEME Publication

Scopus Indexed

\title{
IOT BASED INTELLIGENT TRASH MONITORING SYSTEM WITH ROUTE OPTIMIZATION METHOD
}

\author{
R. Sai Nithesh Varma, P. Jyothi Swaroop, B. Karthik Anand, Nikhil Yadav \\ Department of Electrical and Electronics Engineering, Amrita School of Engineering, \\ Coimbatore, Amrita Vishwa Vidyapeetham, India
}

\section{N. Janarthanan}

Assistant Professor, Department of Electrical and Electronics Engineering, Amrita School of Engineering, Coimbatore, Amrita Vishwa Vidyapeetham, India

\section{T.V Sarath}

Assistant Professor, Department of Electrical and Electronics Engineering, Amrita School of Engineering, Coimbatore, Amrita Vishwa Vidyapeetham, India

\begin{abstract}
Waste Management has become a difficult task for Municipal Co-operation. It is observed that the practice of trash collection is quite inefficient and ineffective in most of the areas in India. This is due to the size of population, economical drawbacks and majorly because of the lack of feedback mechanisms. A proper well-designed system that monitors the filling of bins in a community will make the work easier for the trash collecting personnel. In this paper, a prototype of a Smart Bin Monitoring System is implemented with the help of ZigBee connectivity in a Star network, NodeMCU, Arduino UNO microcontroller and the weight and distance sensors. The software side of the project, is based on the waste fill status of each bin, an algorithm for optimized path is developed using MATLAB GUI. Also, the bin values and the monitored parameters are made accessible to the households and waste collectors via an APP developed using the MIT App Inventor.
\end{abstract}

Key words: IoT Smart Bin, Trash Monitoring, Route Optimization, MATLAB GUI, ZigBee, NodeMCU, Arduino UNO and Firebase

Cite this Article: R. Sai Nithesh Varma, P. Jyothi Swaroop, B. Karthik Anand, Nikhil Yadav, N. Janarthanan and T.V Sarath, IoT Based Intelligent Trash Monitoring System with Route Optimization Method, International Journal of Electrical Engineering and Technology, 11(4), 2020, pp. 57-65.

https://iaeme.com/Home/issue/IJEET?Volume $=11 \&$ Issue $=4$ 


\section{INTRODUCTION}

Unsustainable handling of solid waste and its disposal on road margins, open spaces, water sources etc., pose numerous potential risks to the human and animal health and the environment. There are also direct health risks involved for those working in the field without proper protection tools such as gloves and other sanitary equipment's. A large percentage of waste collectors and individuals who reside in the vicinity disposal sites are infected with gastrointestinal parasites, worms, and other harmful waste-related biological problems [1]. People already possess a lot of health risks because of the poor quality of air and water. Besides, the infrequent collection of waste would prove to be a breeding ground for flies and rats [2]. The environmental problem caused by solid waste is aesthetic. The collection of garbage in various place have become hideous and unorganized. Trash collection department is unable to go through every corner of the site as they are unaware of the levels of trash present at each house. This creates a problem as the waste in the respective residence or locality piles up and becomes infectious and a source of contagious disease which will affect the nearby people. Waste quantity monitoring is one of the first steps required for management of waste resources. Thus, we need dedicated, and planned Smart bin IoT nodes that will ensure that the waste is collected from all households in a timely and optimized manner that saves time, transport, workforce and other costs, all while keeping track of waste generation statistics, which will help deciding the setup cost of recycling center and predicting collection time.

\section{SYSTEM OVERVIEW}

The proposed IoT based Intelligent Trash Monitoring System consists of different modules viz., Data Collection, Transmission Module, Route Optimization Module and App Interface Module as shown in Fig.1 [3],[4].

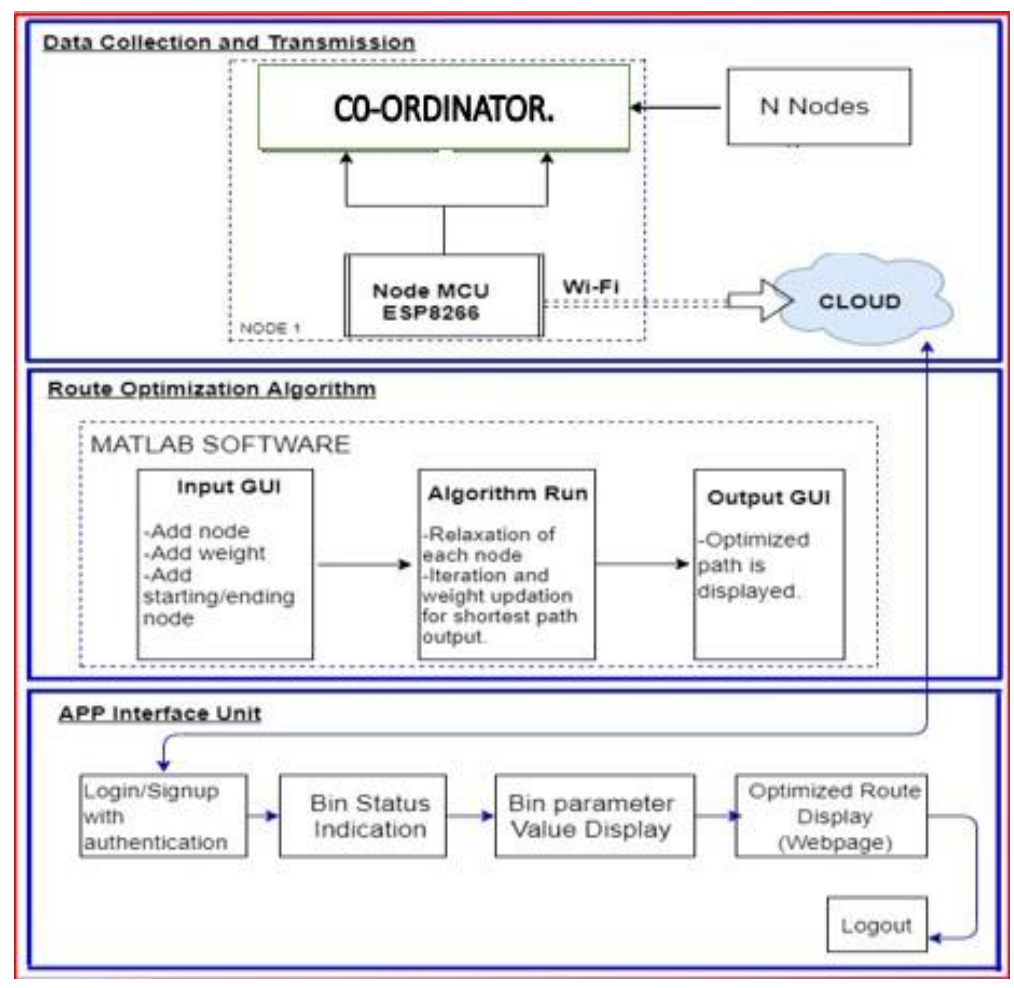

Figure 1 Overall System Design. 


\subsection{Data Collection and Transmission}

The data will be collected from the smart bins present at each house. The smart bins will have sensors that calculate the weight and level of the waste in the bin [3]. For getting the level of the trash, an ultrasonic sensor is used and for the weight, a load cell is used. The load cell is a sensor or a transducer consisting of strain gauges connected in the form of a Wheatstone bridge. The voltage of the bridge is minimal to amplify which, HX711 amplifier is used. For each sensor, a threshold is set crossing which the specific bin is tagged, meaning it has to be cleared. LCD is placed to display the values of the weight and height of the bin. The smart bin module diagram is shown in Fig.2 [3].

Once the data is gathered and processed in the system, it is transmitted using the Zigbee module. Zigbee is best suited reason being it creates a star network/local area network which is used to communicate within the system. Each bin will have a ZigBee which acts as a router and these router ZigBee's communicate with the coordinator Zigbee[9] which is connected to the NodeMCU, which acts as a gateway to transmit the bin data to the Firebase (a real-time database which stores the bin data) which can later be accessed by the app[10]. An end to end transmission of data takes place [11]. The data from each node (smart bin) is put through this process. In fig.3, the smart bin module is shown with the Zigbee transmitter.

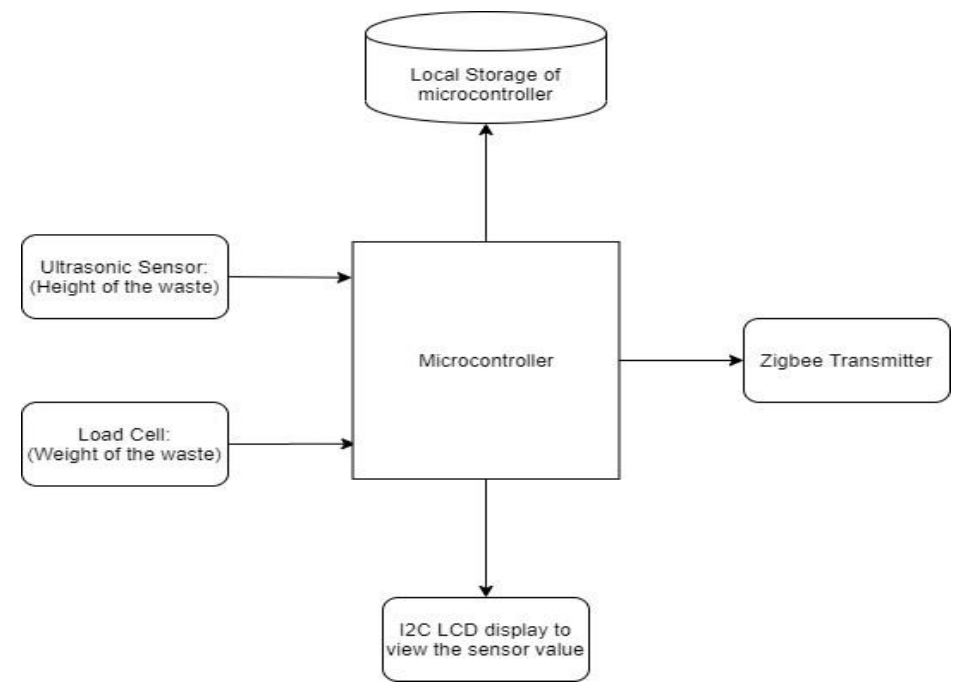

Figure 2 Smart Bin Module

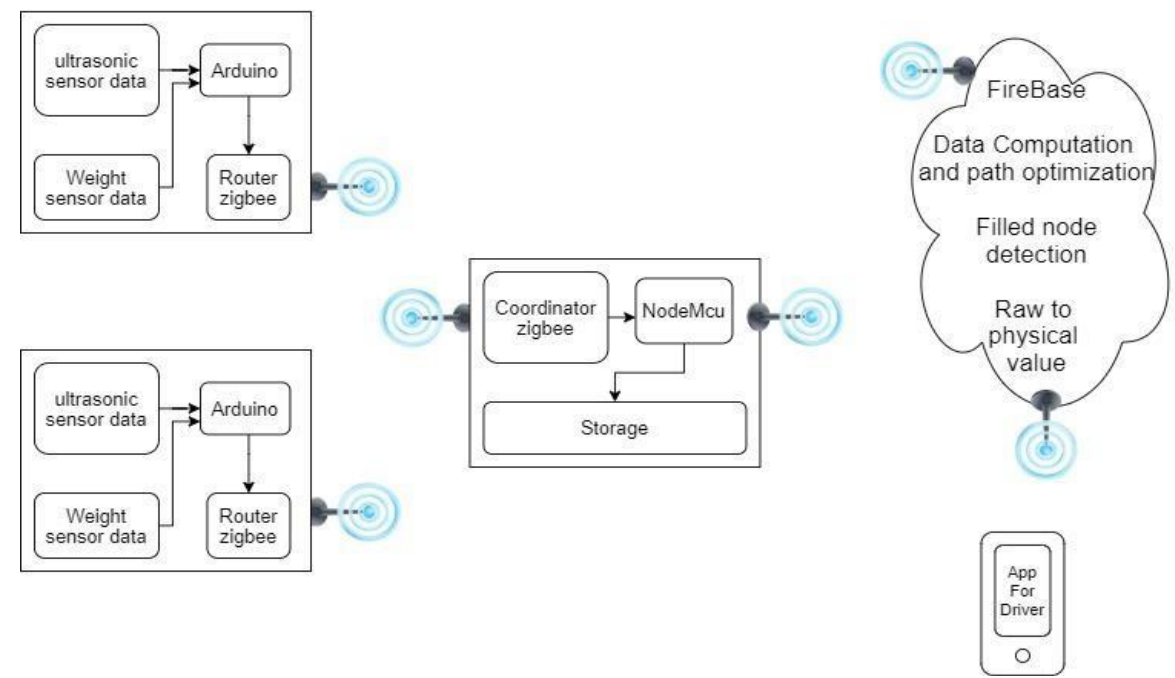

Figure 3 Zigbee Transmission between the modules. 


\subsection{Route Optimization Algorithm}

The route optimization for the system would require many smart bin modules to be set up at different locations which is not quite viable. So, for the illustration of the working of the system we have designed the optimization algorithm, where the nodes (smart bins) are given as an input to the algorithm and the path is given as the output after the algorithm is processed.

The best-suited optimization algorithm for this system is the Dijkstra's algorithm. The shortest path to clear the bins is shown from source node to the final node. The weight between the nodes is decided based on the priority of the one which has to be cleared first. If a node (bin) is to be cleared then the weight of the nodes connected to it is set as low. The algorithm is designed using MATLAB GUI where the number of nodes and the weights between the nodes are input by the user and the optimized path is achieved using the Dijkstra's algorithm in MATLAB. The flowchart of the logic of the Dijkstra's algorithm is shown in fig.4.

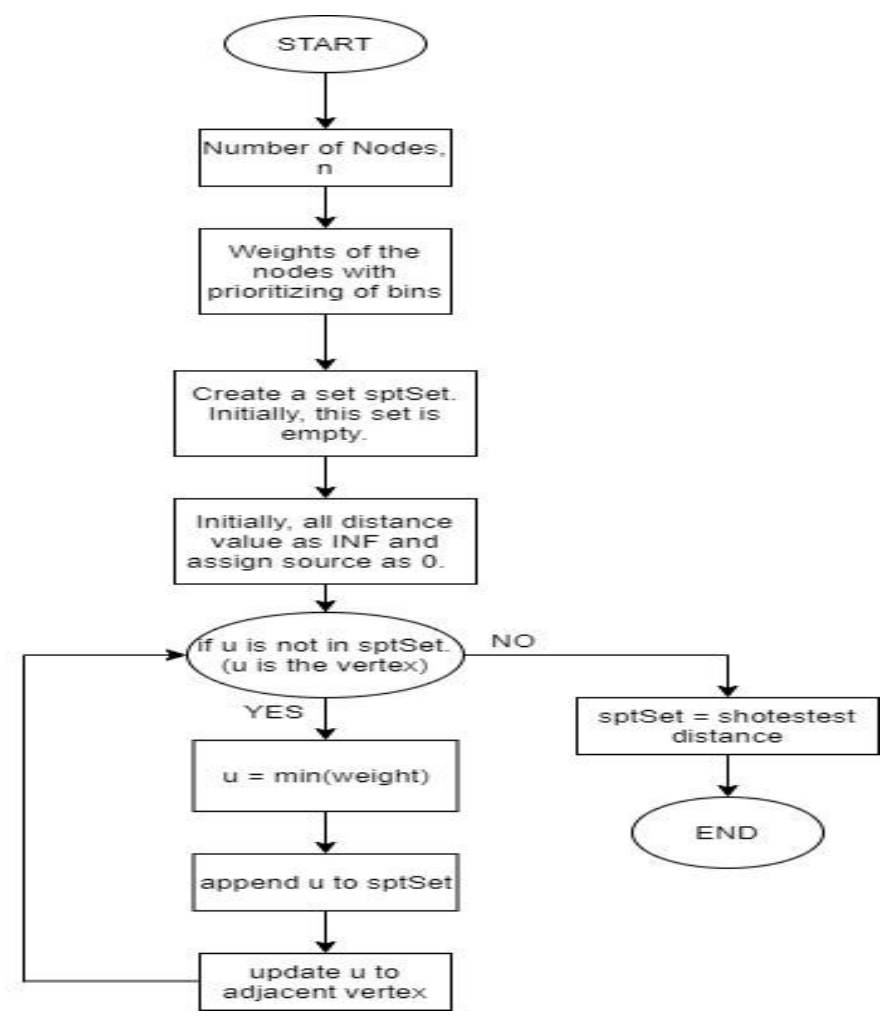

Figure 4 Dijkstra's Algorithm Flowchart

\subsection{App Development}

The app primarily functions as an easy-to-use interface for displaying the bin data, received from the Firebase database. MIT App Inventor, an open-source App development platform has been used for creating the app prototype. Firebase is a real-time database platform, developed by Google, which helps in secure storage and flexible transmission of the data received from the NodeMCU. The NodeMCU is used for processing and collecting the realtime data which will be sent to the Firebase. The MIT App Inventor employs a concept similar to the Scratch programming language, developed by MIT. The coding of the app is done by picking and placing blocks, whereas the Designer tab is used for the construction, design and arrangement the basic app UI (User Interface). 
R. Sai Nithesh Varma, P. Jyothi Swaroop, B. Karthik Anand, Nikhil Yadav, N. Janarthanan and T.V Sarath

\section{HARDWARE IMPLEMENTATION}

The hardware implementation included the setup of the smart bin system. The components used for the system is shown in table.1 (this is for one smart bin module). Similarly, there are two modules designed for this project.

Table 1 Components Used for Smart Bin Module

\begin{tabular}{|c|l|l|}
\hline S. No & \multicolumn{1}{|c|}{ Component } & \multicolumn{1}{c|}{ Action } \\
\hline 1. & Arduino Uno & $\begin{array}{l}\text { upC-Receives, process and send sensor data to } \\
\text { Zigbee. }\end{array}$ \\
\hline 2. & Load Cell & Measure the weight of the bin \\
\hline 3. & Ultrasonic Sensor & Measures the height of the bin \\
\hline 4. & Zigbee (Router) & Sends the data to the Coordinator Zigbee \\
\hline 5. & $\begin{array}{l}\text { Zigbee (Co- } \\
\text { Coordinator) }\end{array}$ & Collects the data and sends it to the NodeMCU \\
\hline 6. & NodeMCU & A gateway to send data to the Firebase. \\
\hline
\end{tabular}

A prototype of the smart bin module has been developed and the same is interfaced with the Zigbee module. The smart bin is developed using the Arduino UNO where the ultrasonic sensor and the load cell are connected to it and the data will be transmitted to the coordinator Zigbee which is connected to the NodeMCU. The NodeMCU transmits the data gathered from the bin to the Firebase where the data is used for further processing. The smart bin module of one such system is shown in fig. 5 and the coordinator Zigbee is shown in fig. 6.

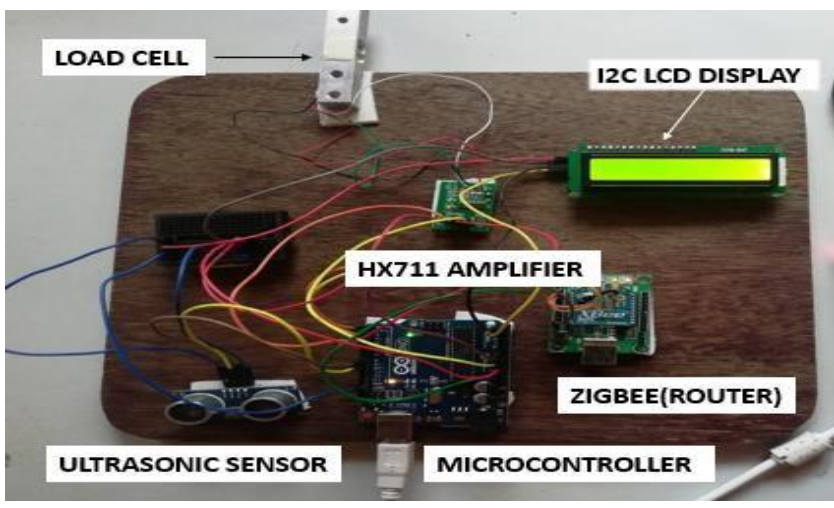

Figure 5 Smart Bin Module.

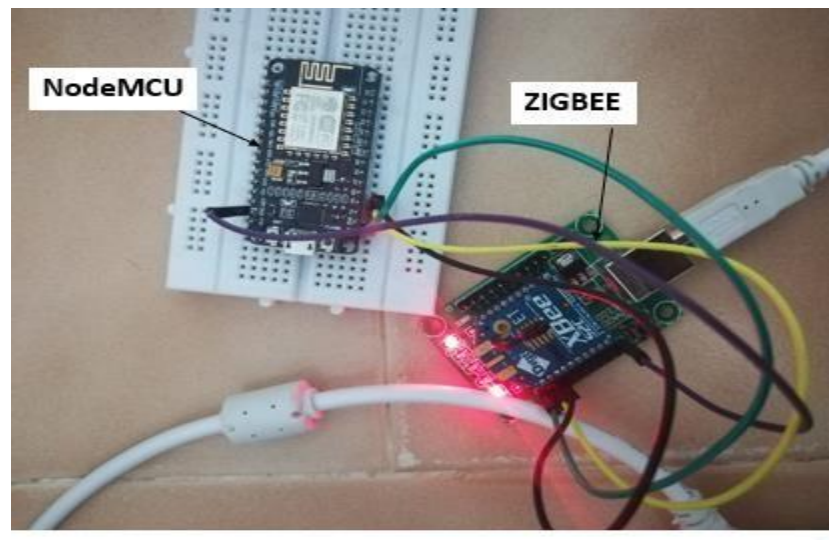

Figure 6 Coordinator Zigbee connected to the NodeMCU 
The data from the router ZigBee will be transmitted to the coordinator Zigbee. This data can be viewed using the XCTU software by connecting the ZigBee to the laptop after the configuration of the ZigBee module. The collected data is stored in the Firebase in the subdivided order shown below in fig.7.

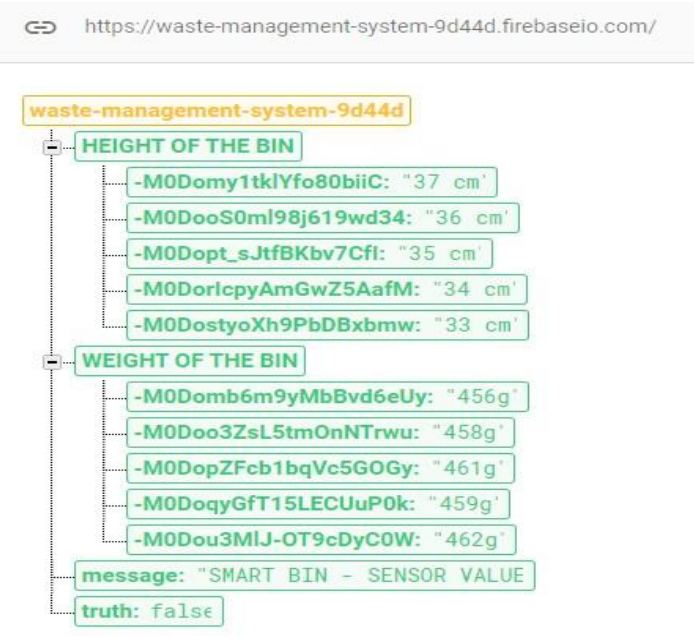

Figure 7 Bin data to the Firebase.

\section{MONITORING OF BINS USING AN APP}

An app is designed to monitor the bins and display the values in the app. The app also has additional features such as the user can create an account using his email and password. The user will be able to view the bins which are filled based on the color of the respective bins which is set using the data present in the Firebase.

The data is stored in Firebase and using the MIT app inventor platform and the stored data is then displayed in the app which displays the bins which have to be cleared with a distinct color. The app layout and the outputs are depicted in fig.8, fig.9, fig.10 and fig.11.
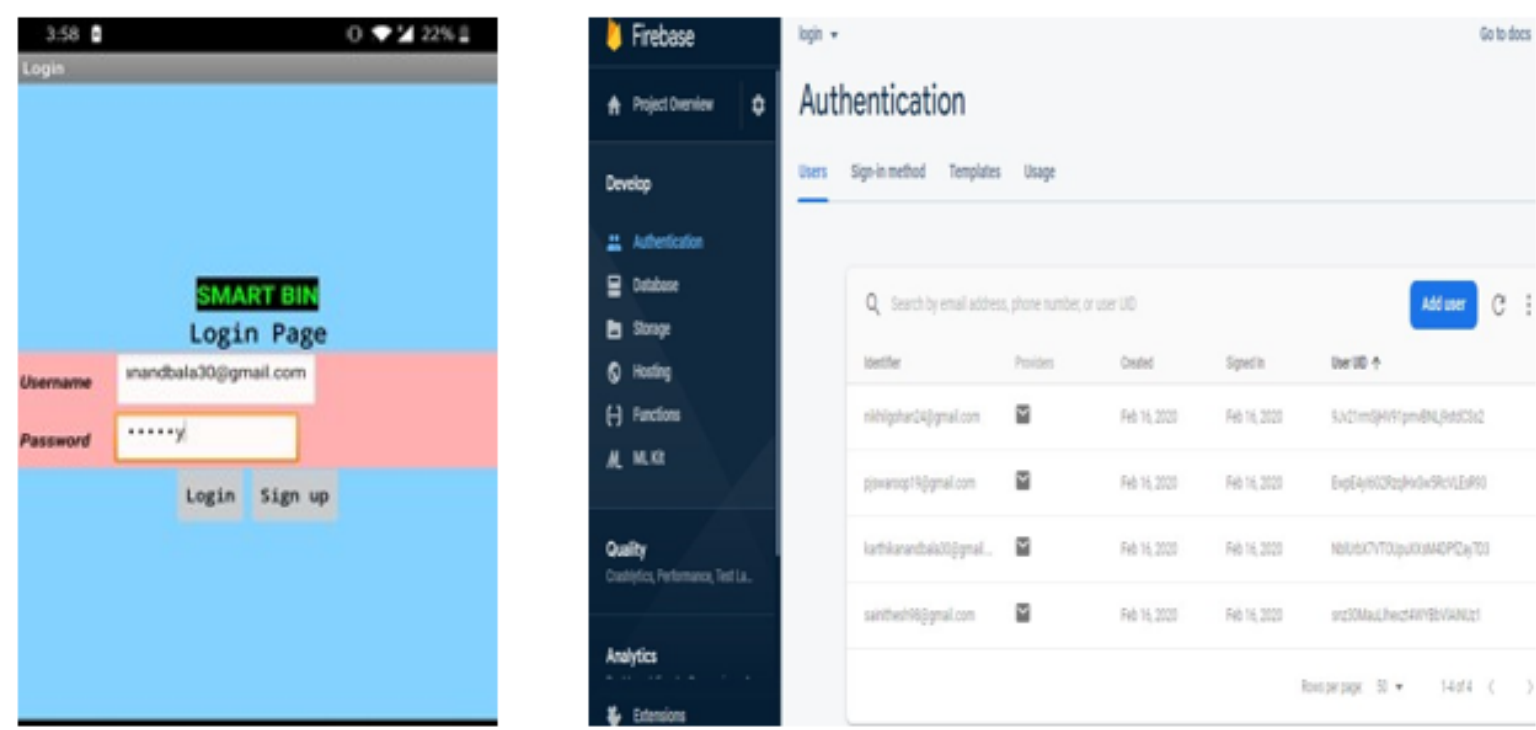

Figure 8 Login Page for the driver. 
R. Sai Nithesh Varma, P. Jyothi Swaroop, B. Karthik Anand, Nikhil Yadav, N. Janarthanan and T.V Sarath
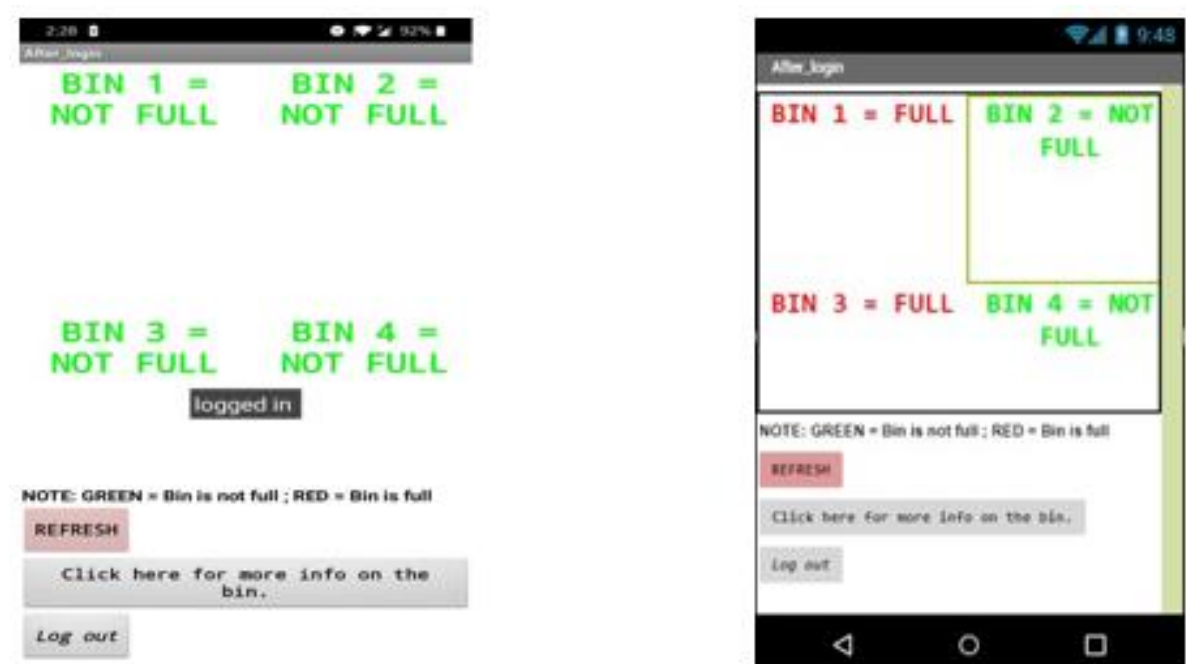

Figure 10 Bin details after login by the driver. Figure 11 The bins which are filled are in red color.

In the fig. 10 and fig.11, the bin status can be monitored. In fig.11, the status of the bins is observed, where the bins which are filled are shown in red color and the bins which are not filled are shown in green color.

To know the values of each bin, the user can click on the "Click here for more info on the bin" button on the app. This will direct the user to a page where he will be able to view the values of each bin. This is shown in fig. 12 .

\section{SOFTWARE IMPLEMENTATION OF DIJKSTRA ALGORITHM}

The Dijkstra's algorithm is implemented in MATLAB GUI. The logic described above is applied in the MATLAB code. The numbered nodes and the weights between the nodes are specified in the GUI as shown in fig. 12.

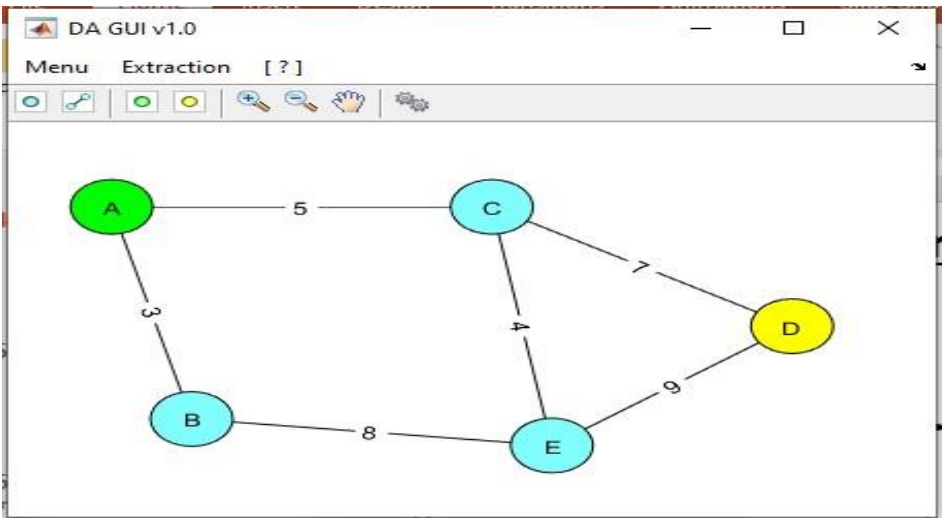

Figure 12 Nodes and Weights between the nodes are specified in the GUI.

After the input to the GUI system, the algorithm is processed and the shortest path is displayed in a distinct color as shown in fig.15. The calculated solution of the algorithm is extracted in the excel sheet as shown in fig.13 and the cumulative shortest distance is also extracted in the excel sheet as shown in fig.14. 


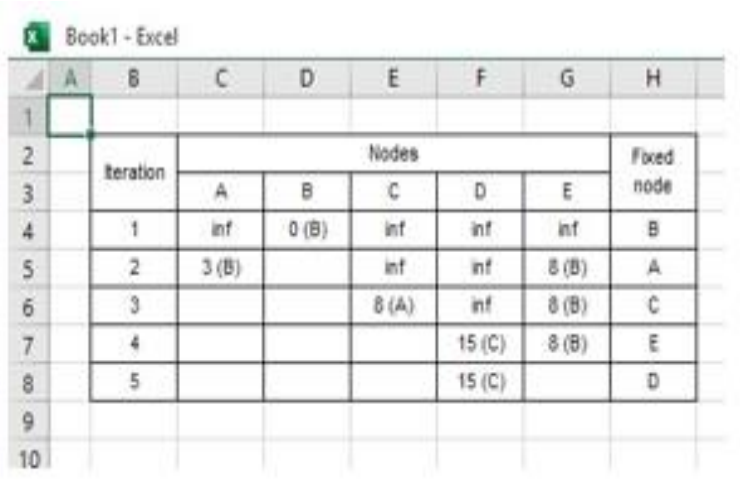

Figure 13 Calculated solution in excel application

\begin{tabular}{|c|c|c|c|c|c|}
\hline$\triangle A$ & B & C & $D$ & $E$ & $\mathrm{~F}$ \\
\hline \multicolumn{6}{|c|}{1} \\
\hline 2 & Nodes & $B$ & A & c & 0 \\
\hline 3 & Distances & 0 & 3 & 5 & 7 \\
\hline 4 & Cunvulted distance & 0 & 3 & 8 & 15 \\
\hline 5 & & & & & \\
\hline r & & & & & \\
\hline
\end{tabular}

Figure 14 Cumulative shortest path in Excel.

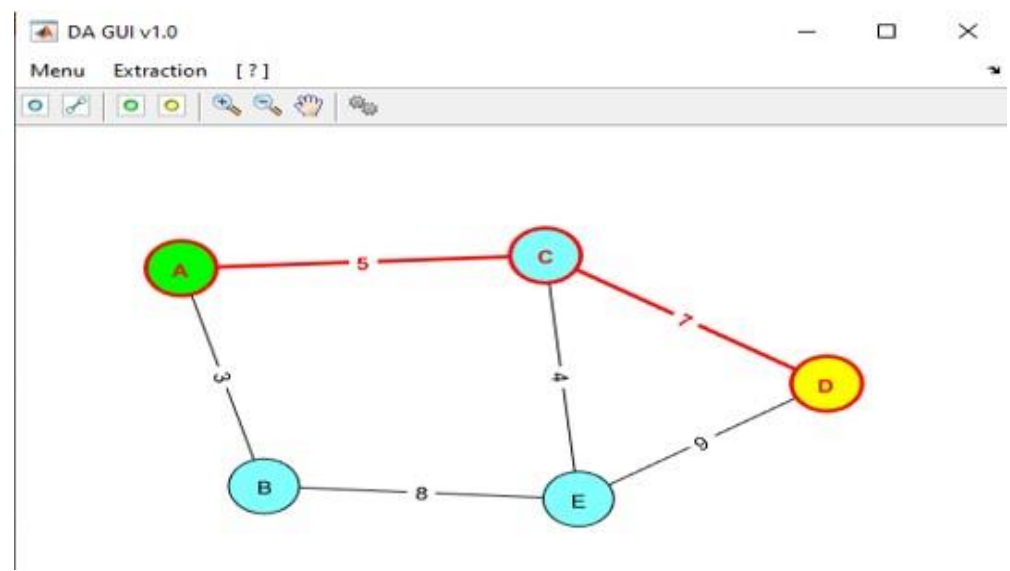

Figure 15 Shortest Path for the given inputs.

The process is implemented and desired output for the shortest path is shown in the MATLAB GUI.

\section{CONCLUSION}

The concept of monitoring the smart bin system using IoT, an app and the algorithm for the optimization path method has been implemented. The app is designed using the MIT app inventor with an easy user interface system. The user can monitor the status of the bin in the app. Through this approach the bin status will be monitored and the shortest path for the user to go will be helpful and efficient. The optimized path using MATLAB GUI makes it easier for the waste collector to collect the bins which are to be cleared taking the shortest path. In the future developments of the project, the hardware can be made maintaining the costefficacy by designing application-specific chips, the algorithm can be designed to cater to various locational and operational variables for optimization and the systems can be integrated to provide an end-to-end solution for a real-time application.

\section{REFERENCES}

[1] C. J. Baby, H. Singh, A. Srivastava, R. Dhawan and P. Mahalakshmi, (2017) "Smart bin: An intelligent waste alert and prediction system using machine learning approach," 2017 International Conference on Wireless Communications, Signal Processing and Networking (Wisp NET), pp. 771-774, IEEE.

[2] N. Sowmya, A. Prof, (2018) "Smart Trash Can Monitoring System using IoT - Creating Solutions for Smart Cities", pp. 238-242. 
R. Sai Nithesh Varma, P. Jyothi Swaroop, B. Karthik Anand, Nikhil Yadav, N. Janarthanan and T.V Sarath

[3] R. Pramudita, H. Heryanto, R. Trias Handayanto, D. Setiyadi, R. W. Arifin and N. Safitri, (2019) "Shortest Path Calculation Algorithms for Geographic Information Systems," Fourth International Conference on Informatics and Computing (ICIC), Semarang, Indonesia, 2019, pp. 1-5.

[4] X. Fang, D. Yang and G. Xue, (2011) "A Distributed Algorithm for Multi-Constrained Anypath Routing in Wireless Mesh Networks," IEEE International Conference on Communications (ICC), Kyoto, 2011, pp. 1-5.

[5] Z. Hisham Che Soh, M. Azeer Al-Hami Husa, S. Afzal Che Abdullah and M. Affandi Shafie, (2019) "Smart Waste Collection Monitoring and Alert System via IoT," IEEE 9th Symposium on Computer Applications \& Industrial Electronics (ISCAIE), Malaysia, pp. 50-54.

[6] M. K. Aparna and P. Sivraj, (2018) "Communication Architecture Framework for A Future Smart Community," 2018 Second International Conference on Intelligent Computing and Control Systems (ICICCS), Madurai, India, pp. 1395-1400, doi: 10.1109/ICCONS.2018.8662896.

[7] G. K. Shyam, S. S. Manvi and P. Bharti, (2017) "Smart waste management using Internetof-Things (IoT)," 2017 2nd International Conference on Computing and Communications Technologies (ICCCT), Chennai.

[8] L. C. S. Paavan, T. G. Sai and M. K. Naga, (2019) "An IoT based Smart Garbage Alert System," 3rd International Conference on Trends in Electronics and Informatics (ICOEI), Tirunelveli, India.

[9] S. K. Memon, F. Karim Shaikh, N. A. Mahoto and A. Aziz Memon, (2019) "IoT based smart garbage monitoring \& collection system using WeMos \& Ultrasonic sensors," 2019 2nd International Conference on Computing, Mathematics and Engineering Technologies (iCoMET), Sukkur, Pakistan.

[10] S. Paul and T. V. Sarath, (2018) "End to End IoT Based Hazard Monitoring System," 2018 International Conference on Inventive Research in Computing Applications (ICIRCA), Coimbatore, pp. 106-110, doi: 10.1109/ICIRCA.2018.8597430.

[11] Snehal R. Shinde, A. H. Karode and Dr. S. R. Suralkar, (2017) Review on-IOT Based Environment Monitoring System, International Journal of Electronics and Communication Engineering and Technology, 8(2), pp. 103-108.

[12] G.Sasi, P.G.Akila, R.ambika and Dr.G.Athisha,(2018) Performance Analysis of IOT Based Smart Sensors in Agriculture, International Journal of Mechanical Engineering and Technology, 9(11), pp. 1936-1942.

[13] Trideep Singha Roy, Soumalya Ghosh, Rimpi Datta, Arpita Santra, (2019) IoT Based Home Automation Using Raspberry PI, International Journal of Computer Engineering and Technology, 10(3), pp. 70-74.

[14] Viswanath Naik.S, S.Pushpa Bai, Rajesh.P, Mallikarjuna Naik.B, (2015), IoT Based Green House Monitoring System, International Journal of Electronics and Communication Engineering \& Technology, 6(6), pp. 45-47 